\title{
Anti-allodynic effect induced by curcumin in neuropathic rat is mediated through the NO-cyclic-GMP-ATP sensitive $\mathrm{K}^{+}$channels pathway
}

Tracy Pastrana-Quintos', Giovanna Salgado-Moreno' ${ }^{1}$, Julia Pérez-Ramos' ${ }^{1}$ Arrigo Coen² and Beatriz Godínez-Chaparro ${ }^{* *}$ (D)

\begin{abstract}
Background: Recent studies pointed up that curcumin produces an anti-nociceptive effect in inflammatory and neuropathic pain. However, the possible mechanisms of action that underline the anti-allodynic effect induced by curcumin are not yet established. The purpose of this study was to determine the possible anti-allodynic effect of curcumin in rats with L5-L6 spinal nerve ligation (SNL). Furthermore, we study the possible participation of the NOcyclic GMP-ATP-sensitive $\mathrm{K}^{+}$channels pathway in the anti-allodynic effect induced by curcumin.

Methods: Tactile allodynia was measured using von Frey filaments by the up-down method in female Wistar rats subjected to SNL model of neuropathic pain.

Results: Intrathecal and oral administration of curcumin prevented, in a dose-dependent fashion, SNL-induced tactile allodynia. The anti-allodynic effect induced by curcumin was prevented by the intrathecal administration of L-NAME (100 $\mathrm{gg} / \mathrm{rat}$, a non-selective nitric oxide synthase inhibitor), ODQ $(10 \mu \mathrm{g} / \mathrm{rat}$, an inhibitor of guanylatecyclase), and glibenclamide (50 $\mathrm{mg} / \mathrm{rat}$, channel blocker of ATP-sensitive $\mathrm{K}^{+}$channels).
\end{abstract}

Conclusions: These data suggest that the anti-allodynic effect induced by curcumin is mediated, at least in part, by the NO-cyclic GMP-ATP-sensitive $\mathrm{K}^{+}$channels pathway in the SNL model of neuropathic pain in rats.

Keywords: Curcumin, Neuropathic pain, Nitric oxide, SNL, Intrathecal administration

\section{Background}

Neuropathic pain is defined as the pain arising as a direct consequence of a lesion or disease affecting the somatosensory system [1]. The prevalence of neuropathic pain in the general population is estimated at $3-17 \%$ [2]. Neuropathic pain could result from different etiologically disorders affecting the peripheral or the central

\footnotetext{
* Correspondence: bgodinez@correo.xoc.uam.mx

'Departamento de Sistemas Biológicos, División de Ciencias Biológicas y de la Salud, Universidad Autónoma Metropolitana-Xochimilco, Calzada del Hueso 1100, Colonia Villa Quietud, 04960 Mexico, D.F., Mexico

Full list of author information is available at the end of the article
}

neurvous system such as metabolic disorders (diabetes), viral infections (post-herpetic neuralgia, HIV, leprosy), neurodegenerative (Parkinson), autoimmune diseases (multiple sclerosis and Guillain-Barre syndrome), a tomor, trauma, esposure to toxinsor hereditary disease [3]. Treatment of neuropathic pain is based on tricyclic antidepressant (amitriptyline), gabapentinoids (gabapentin and pregabalin) and selective serotoninnorepinephrine reuptake inhibitors (duloxetine and venlafaxine) as the first-line treatment. Lidocaine, capsaicin, and tramadol have been proposed as the second-line treatment, while morphine, oxycodone and botulinum

(c) The Author(s). 2020 Open Access This article is licensed under a Creative Commons Attribution 4.0 International License, which permits use, sharing, adaptation, distribution and reproduction in any medium or format, as long as you give appropriate credit to the original author(s) and the source, provide a link to the Creative Commons licence, and indicate if changes were made. The images or other third party material in this article are included in the article's Creative Commons licence, unless indicated otherwise in a credit line to the material. If material is not included in the article's Creative Commons licence and your intended use is not permitted by statutory regulation or exceeds the permitted use, you will need to obtain permission directly from the copyright holder. To view a copy of this licence, visit http://creativecommons.org/licenses/by/4.0/ The Creative Commons Public Domain Dedication waiver (http://creativecommons.org/publicdomain/zero/1.0/) applies to the data made available in this article, unless otherwise stated in a credit line to the data. 
Toxin-A were included as third-line treatments for neuropathic pain [1]. Unfortunately, the treatment for neuropathic pain is inadequate due to poor drug efficacy and tolerability. Therefore, it is necessary to study more alternative therapies to mitigate neuropathic pain.

Curcumin [1,7-bis (4-hydroxy-3-methoxyphenyl)hepta-1,6-diene-3,5-dione] is an organic compound from the rhizome of the Indian spice turmeric (Curcuma longa), which is one of the principal ingredients in curry powder [4]. Its wide spectrum of biological activities including antiviral [5], antioxidant [6], neuroprotective [7], antidepressant [8], and anti-inflammatory effects [9]. In addition, curcumin has shown an anti-nociceptive effect in different types of pain, such as inflammatory pain [4, 7, 10], visceral pain [11], musculoskeletal pain [12], burning pain [13], and neuropathic pain [14-17]. Curcumin may alleviate neuropathic pain through inhibiting the expression of CX3CR1 by the activation of $N F-\kappa \beta$ p65 in the dorsal horn of the spinal cord and dorsal root ganglion (DRG) [16]. Moreover, curcumin reversed the development of mechanical allodynia suppressing the activation of ERK and JNK in the spinal DRG [15]. Also, curcumin has an anti-allodynic effect through the noradrenergic and serotonergic systems by activation of the $\beta_{2}$-adrenoceptor and $5-\mathrm{HT}_{1 \mathrm{~A}}$ receptor, respectively [17]. Curcumin decreased calcium ion accumulation in the sciatic nerve, decreased nitric oxide (NO) and lipid peroxidation (LPO), and increased endogenous antioxidant enzymes in vincristine-induced neuropathic pain [18]. Several lines of research indicated that NO induces analgesia and also that it mediates the peripheral and central anti-nociceptive effect of analgesic compounds, such as opioids, non-steroidal anti-inflammatory drugs, and natural products [19]. Other studies have reported that drugs which activate the NO-cGMP pathway seem to modulate the opening of the $\mathrm{K}^{+}$channels in order to produce nociception [20]. Previous studies have indicated that natural products produce anti-nociceptive and anti-allodynic effects through the NO-cGMP-ATP sensitive channels $\mathrm{K}^{+}$pathway [20-26]. There is evidence that suggests that curcumin exhibits its anti-nociceptive effect by directly stimulating $\mathrm{K}^{+}$ATP channels in an inflammatory pain model [27]. Therefore, this work was undertaken to determine the possible anti-allodynic effect of curcumin in rats with spinal nerve ligation (SNL) model of neuropathy. Moreover, we investigated whether, at the central level, the NO-cGMP-ATP sensitive channels $\mathrm{K}^{+}$pathway participates in the antiallodynic effect induced by curcumin.

\section{Methods}

\section{Animals}

All experiments were performed on female Wistar rats weighing $140-160 \mathrm{~g} \quad(n=162)$. Previous studies have demonstrated no difference in tactile allodynia between female and male rats in the SNL model [23, 28, 29]. For this reason, we decided to use female rat in this study. The animals were provided by our bioterium and kept in isolated cages; rats were maintained with food (Lab Diet 5001) and water ad libitum. They were housed in groups at $22 \pm 2{ }^{\circ} \mathrm{C}$ under 12:12 light-dark cycles. All experimental protocols were approved by the Research Bioethics Committee of the UAM-X. Animals were cared for the according to the current procedure for the Care and Use of Laboratory Animals (NOM-062-ZOO-1999, Mexico), and by the Guidelines on Ethical Standards for Investigation of Experimental Pain in Animals [30]. The rats were acclimatised to laboratory condition for 1 week prior to experiments, and the experiments were conclucted at 9: 00 to $14: 00$. At the end of the experiments, rats were euthanised in $\mathrm{CO}_{2}$ chamber.

\section{L5-L6 spinal nerve ligation model}

To induce neuropathic pain, left L5 and L6 spinal nerve were performed as describe Kim and Chung (1992). Rats were anesthetized with a mixture of Ketamine $(45 \mathrm{mg} /$ kg, i.p) + Xylaxine (12 mg/kg, i.p.), a longitudinal skin incision was made on the left side of the spinal L4 to L6 level. Afterward, L5 and L6 spinal nerve were isolated and tightly ligated with 4-0 silk suture distal to the dorsal root ganglion. In sham surgery was concluded exposing L5 and L6 nerves but not ligated. Incisions were closed, and rats were allowed to recover for 14 days [31].

\section{Measurement of anti-allodynic activity}

Tactile allodynia was evaluated by measuring paw withdrawal threshold. The von Frey filaments were applicated vertically for $10 \mathrm{~s}$ to the plantar surface on the right hind paw. The tactile allodynia was determinated by a positive response such as an abrupt widrawal hind paw. The cut-off value was a negative response to $15 \mathrm{~g}$. the paw withdrawal threshold was determinated using the up-down method with an application of a series of consefutive von Frey filaments $(0.4,0.7,1.2$, 2.0, 3.6, 5.5, 8.5 , and $15 \mathrm{~g}$ ). The resulting scores were used to calculate the $50 \%$ response threshold using the formula:

$$
50 \% \text { threshold }=10^{\left(X_{f}+\kappa \delta\right)} / 10,000 .
$$

where $\mathrm{X}_{\mathrm{f}}=$ the value (in log units) of the final von Frey filament used, $k=$ the value from the table for the pattern of positive and negative responses published previously by Chaplan and co-workers (1994), and $\delta=$ the mean difference (in log units) between stimuli [32]. The $50 \%$ threshold withdrawal was assessed before and at 0 , 30, 60, 120 and $240 \mathrm{~min}$ after drug administration. Allodynia was considered present when the paw withdrawal threshold was <4g [32, 33]. Animals with a basal 
withdrawal threshold above $4 \mathrm{~g}$ or that showing motor deficiency were not included in the experiments.

\section{Drugs}

Curcumin (C1386), glibenclamide (G0639), N-nitro-Larginine methyl ester (L-NAME, N5751), $1 \mathrm{H}-[1,2,4]$ oxadiazolo [4,3-a]quinoxaline-1-one (ODQ, O3636), $\mathrm{NaOH}$ (S5881), and Dimethyl sulfoxide (DMSO, 67-685) were purchased from Sigma Aldrich (St. Louis, MO, USA). Curcumin used for per oral (p.o.) administration was dissolved in $\mathrm{NaOH}$ to $0.5 \mathrm{M}$ into a volume of $10 \mathrm{ml} /$ $\mathrm{kg}$. Moreover, curcumin and glibenclamide were dissolved in 10\% DMSO, and ODQ and L-NAME were dissolved in isotonic saline.

\section{Lumbar puncture}

The rats were anaesthetized with $2 \%$ isoflurane and received an intrathecal injection by lumbar puncture 14 days after spinal nerve ligation of L-5/L6, as previously reported by Mestre and co-workers (1994). The animals were holding with one hand at the pelvic girdle level and the drug was injected intrathecally with a $30-\mathrm{G}$ needle connected to a $25-\mu \mathrm{l}$ Hamilton syringe in the intrathecal space between the L5 and L6 vertebrae on the dorsal side and perpendicular to the vertebral column [34].

\section{Study design}

In order to determine the possible anti-allodynic effects of curcumin on neuropathic pain, we used 162 neuropathic rats that were randomly divided into the following groups: SNL $(n=6)$ and sham $(n=6)$ animals received $20 \mu \mathrm{l}$ of a vehicle (saline at $0.9 \%$ ) via intrathecal administration (i.t.) or increasing doses of curcumin via i.t. (30, 100,200 , and $300 \mu \mathrm{g} / \mathrm{rat} ; n=6$ per group). On the other hand, SNL $(n=6)$ and sham $(n=6)$ animals received an oral $(2 \mathrm{ml})$ administration of vehicle (carboxymethylcellulose) or increasing doses of curcumin (10, 100, 310 $\mathrm{mg} / \mathrm{kg}$, p.o.); $n=6$ per group). In both cases, the effect of curcumin on the paw withdrawal threshold was evaluated by the up-down method at $0,30,60,120$, and 240 min after intrathecal or oral administration. The doses and drug administration schedules for curcumin were selected based on a pilot experiment in our laboratory. Intrathecal $(100 \mu \mathrm{g} / \mathrm{rat}, n=6,[35])$ or oral $(100 \mathrm{mg} / \mathrm{kg}$, $n=6$, [36]) gabapentin was used as a positive control.

In order to determine the possible participation of the NO-cGMP-ATP-sensitive $\mathrm{K}^{+}$channel pathway in the curcumin-induced anti-allodynic effect, we administrated the nonselective NO synthase inhibitor L-NAME in doses of (10 and $100 \mu \mathrm{g} / \mathrm{rat} ; n=6$, [37]), the guanylyl cyclase inhibitor ODQ in doses of ( 1 and $10 \mu \mathrm{g} / \mathrm{rat} ; n=$ 6, [37]), and an ATP-sensitive $\mathrm{K}^{+}$channel blocker glibenclamide in doses of ( 5 and $50 \mu \mathrm{g} / \mathrm{rat} ; n=6$, [37]). The anti-allodynic effect of the co-administration of antagonists and curcumin was evaluated at $0,30,60$, 120 , and $240 \mathrm{~min}$ after administration.

\section{Data statistical analysis}

In the experiments using the von Frey withdrawal threshold, curves were constructed as the mean \pm S.E.M plotting the $50 \%$ withdrawal threshold as a function of time. Moreover, to analyse the effect of the different treatment, the data were normalized by calculating the area under the 50\% withdrawal threshold against time curves (AUC). The area under the 50\% withdrawal threshold against the time curve (AUC) was calculated by the trapezoidal rule. The percentage of maximum possible effect (\%MPE) was calculated with the following formula:

$$
\% \mathrm{MPE}=\frac{\text { AUC Drug-AUC Vehicle }}{\text { AUC Sham-AUC Vehicle }} \times 100
$$

Statistical differences between groups were determined by one-way analysis or two-way repeated measures analysis of variance followed by a post-hoc test; we applied Tukey's post-hoc test for one-way analysis experiments and Bonferroni post-hoc test for two-way analysis experiments. Differences were considered as statistically significant when $P \leq 0.05$.

\section{Results}

14 days after the ligation of the L5-L6 spinal nerves (SNL), the basal values of the $50 \%$ paw withdrawal threshold was disminished $(\leq 4 \mathrm{~g})$ in the ipsilateral paw as compared to sham group (15 g), indicating that the ligation of the L5-L6 spinal nerves induced tactile allodynia. It was observed from days 1 to 14 (Fig. 1a). Fourteen days after the SNL surgery, oral administration with curcumin $310 \mathrm{mg} / \mathrm{kg}$, but not the lower doses (10 and 100 $\mathrm{mg} / \mathrm{kg}$ ) or vehicle, significantly reversed the tactile allodynia in neuropathic rats (Fig. $1 \mathrm{a}, \mathrm{F}_{12,80}=12.9, P<$ 0.0001). In addition, intrathecal administration with curcumin, but not the vehicle, significantly reversed the allodynia in SNL rats in a dose-dependent fashion (Fig. 1c, $\left.F_{15,100}=25.74, P<0.0001\right)$. Oral $(100 \mathrm{mg} / \mathrm{kg})$ and intrathecal $(100 \mu \mathrm{g} / \mathrm{rat})$ administration with an effective gabapentin dose, used as a positive control, significantly reversed tactile allodynia in $46.05 \pm 7.9 \%$ and $77.5 \pm 3.7 \%$, respectively (Fig. 1). The dose of $310 \mathrm{mg} / \mathrm{kg}$ curcumin (p.o.) had $17.2 \pm 2.2 \%$ of the maximum possible antiallodynic effect (\%MPE) compared with $46.05 \pm 7.9 \%$ of the $\% \mathrm{MPE}$ induced by gabapentin (Fig. $1 \mathrm{~b}, \mathrm{~F}_{6}, 30=167.0$, $P<0.0001)$. Moreover, intrathecal administration with curcumin $(300 \mu \mathrm{g} / \mathrm{rat}$, i.t. $)$ produced a maximal effect of about $82.0 \pm 4.3 \%$, whereas gabapentin produced an efficacy of $77.5 \pm 3.7 \%$ (Fig. $1 d, F_{7,38}=244.6, P<0.0001$ ). In both cases, the maximal anti-allodynic effect occurred 


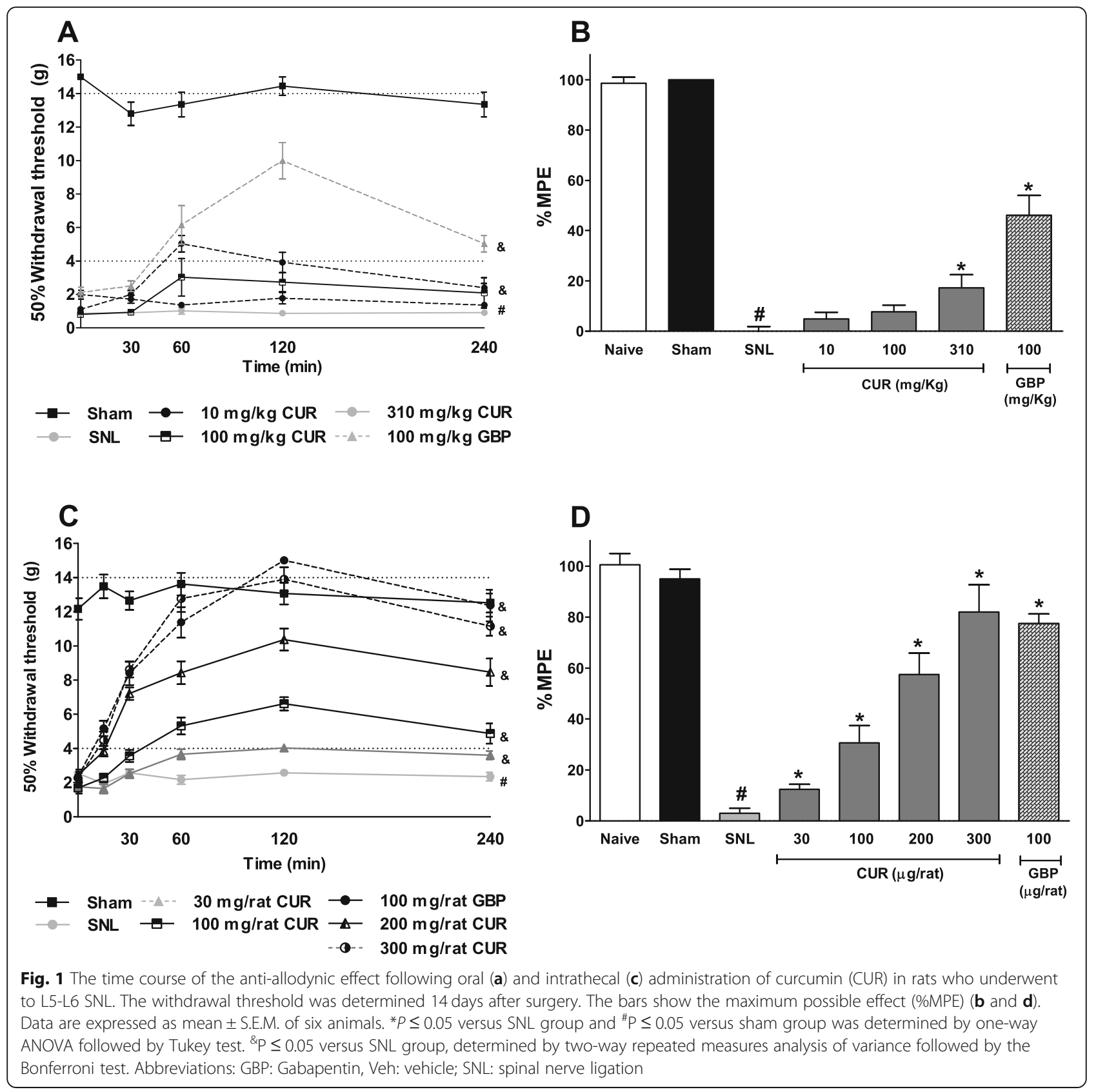

120 min after the oral (Fig. 1a) or intrathecal (Fig. 1c) administration of curcumin and gradually declined in about $4 \mathrm{~h}$.

Effect of L-NAME, ODQ, and glibenclamide on curcumininduced anti-allodynic effect

Intrathecal pre-treatment with L-NAME $(100 \mu \mathrm{g} / \mathrm{rat}$, Fig. 2a, $\mathrm{F}_{15,100}=26.36, P<0.0001$ and $\left.2 \mathrm{~b}, \mathrm{~F}_{6,34}=422.8, P<0.0001\right)$, ODQ $\left(10 \mu \mathrm{g} / \mathrm{rat}\right.$, Fig. $2 \mathrm{c}, \mathrm{F}_{15,100}=27.84, P<0.0001$ and $2 \mathrm{~d}$, $\left.\mathrm{F}_{6,35}=583.2, P<0.0001\right)$ or glibenclamide $(50 \mu \mathrm{g} /$ rat, Fig. $2 \mathrm{e}$ $\mathrm{F}_{15,100}=27.06, P<0.0001$ and $\left.2 \mathrm{f}, \mathrm{F}_{6,34}=421.9, P<0.0001\right)$, significantly prevented the anti-allodynic effect of curcumin
(300 $\mu \mathrm{g} / \mathrm{rat})$ in neuropathic rats. Tukey's test also confirm these differences between treatment groups (Fig. 2a, c, and e). The administration of L-NAME, ODQ, and glibenclamide per se did not affect the allodynia induced by L5-L6 SNL (Fig. 2).

\section{Discussion}

Acute intrathecal administration of curcumin, but not oral administration, reversed, in a dose-dependent fashion, established tactile allodynia in SNL rats. These results were consistent with previous studies which demonstrated that acute or chronic intrathecal 
A

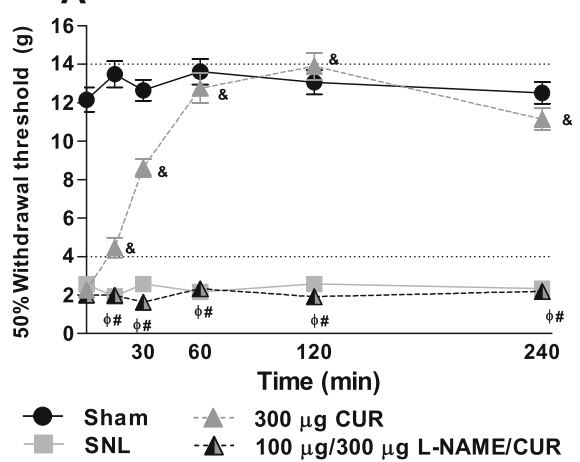

C
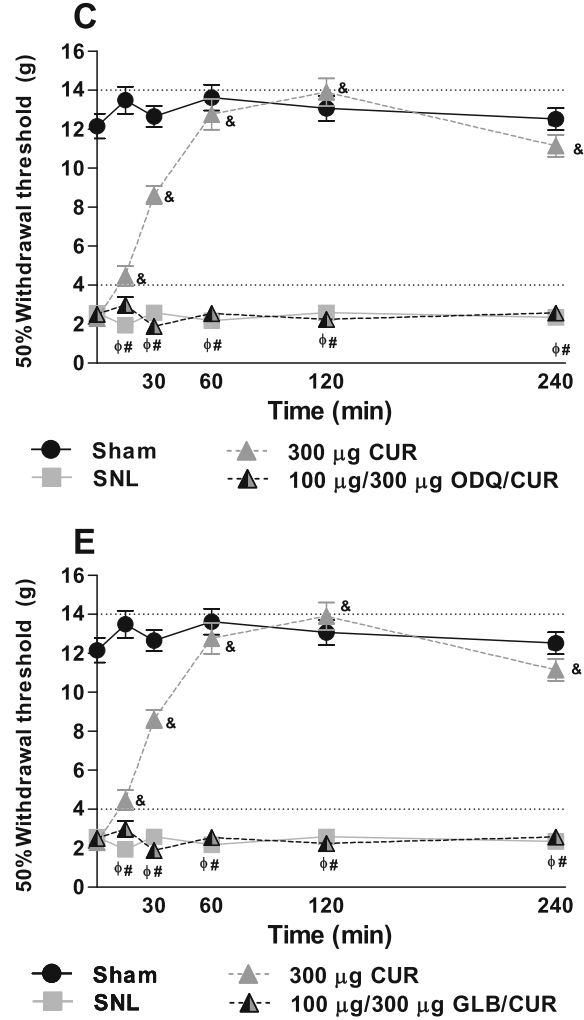

\section{B}

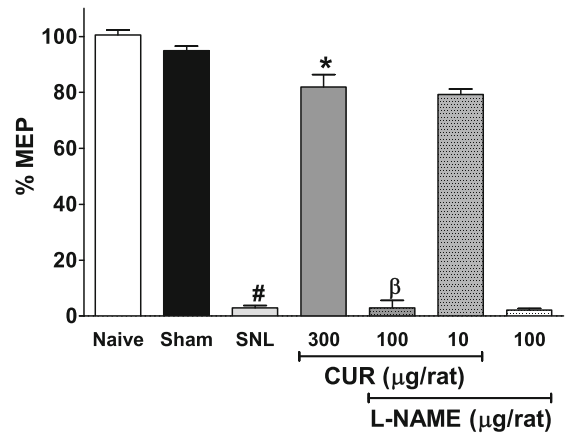

D

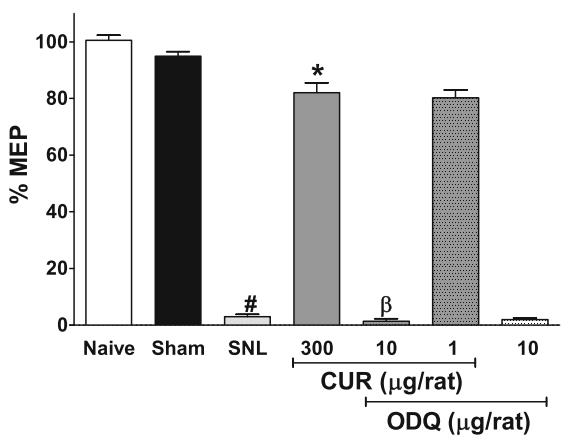

F

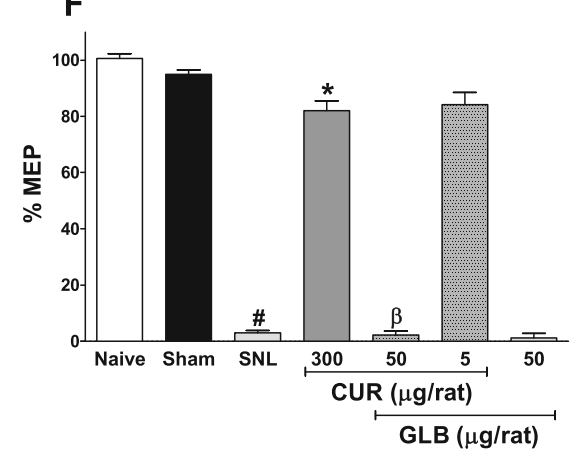

Fig. 2 Time course of the effect of intrathecal pretreatment with the inhibitor of oxide nitric synthase, L-NAME (a); the selective inhibitor of guanylate cyclase soluble, ODQ (c); and the blocker of ATP sensitive $\mathrm{K}^{+}$channels, glibenclamide (GLB) (e); on the anti-allodynic effect induced by curcumin (CUR) in rats who underwent to L5-L6 spinal nerve ligation (SNL). Data are expressed as mean \pm S.E.M. of six animals. The withdrawal threshold was determined 14 days after surgery. The bars show the maximum possible effect (\%MPE). *P $\leq 0.05$ versus SNL group and ${ }^{\# P} \leq 0.05$ versus Sham group and ${ }^{\beta} P \leq 0.05$ versus CUR, determined by one-way ANOVA followed by Tukey test. ${ }^{\&} P \leq 0.05$ versus SNL group and ${ }^{\Phi} P \leq 0.05$ versus CUR group was determined by two-way repeated measures analysis of variance followed by the Bonferroni test. Abbreviations: L-NAME: Nw-nitro-L-arginine methyl ester; ODQ: 1H -[1, 2, 4] oxadiazolo [4,3-a]quinoxalin-1-one; SNL: spinal nerve ligation

administration of curcumin reversed allodynia and hyperalgesia induced by L5-L6 spinal nerve ligation, chronic constriction injury, or in complete Freund's adjuvant models [4, 38]. Additionally, chronic, but not acute, oral curcumin treatment alleviated mechanical allodynia and thermal hyperalgesia in the neuropathic pain model [17]. Moreover, curcumin attenuated the CFA-induced mechanical allodynia and heat hyperalgesia
[4]. Taken together, these data suggest that curcumin could be useful to relieve neuropathic pain in rats.

\section{Curcumin-induced anti-allodynic effect following} administration of L-NAME, ODQ, and glibenclamide

Previous studies have suggested the possible role of the NO-cGMP pathway in activating targets such as potassium channels [19]. The opening of $\mathrm{K}^{+}$channels due to the L-arginine-NO-cGMP pathway allows regulation of 
neuronal excitability through $\mathrm{K}^{+}$ions permeating the membrane [39]. Furthermore, several studies have shown that the opening of $\mathrm{K}^{+}$channels induces antinociception $[36,40]$. In order to study whether curcumin leads to an increase of NO synthesis, L-NAME, a non-selective NOS inhibitor was utilised, blocking the synthesis of NO [36]. It was observed that L-NAME prevented the spinal anti-allodynic effect induced by curcumin in a dose-dependent fashion, suggesting that $\mathrm{NO}$ is an important mediator. In addition, the administration of ODQ, an inhibitor of the soluble guanylyl cyclase enzyme, prevented, in a dose-dependent fashion, the spinal anti-allodynic effect of curcumin. Taken together, our data suggest that curcumin is able to induce the anti-allodynic effect by increasing NO and cGMP production. Nevertheless, some reports indicate that curcumin inhibits NO production with concomitant down-regulation of iNOS mRNA in LPS-activated RAW 264.7 macrophages and LPS-stimulated microglia cell $[41,42]$. However, several studies indicate that the NO/ cGMP signalling cascade has either anti - or proallodynic effects in neuropathic pain models, as well as opposing effects in peripheral inflammatory models [19, 41, 43]. The different effects of the NO-cGMP signal cascade concerning noxious transduction may be due, at least in part, to differences in experimental conditions. In addition, the intrathecal glibenclamide administration prevented the anti-allodynic effect of curcumin in the L5-L6 spinal nerve ligation model. These results suggest that curcumin produces an anti-allodynic effect by activating $\mathrm{K}^{+}$ATP-sensitive channels. According to these findings, previous observations of De Paz-Campos and co-workers (2012) show that curcumin is able to produce anti-nociceptive effects through activation of $\mathrm{K}^{+}$ ATP sensitive channels in an inflammatory model of pain [27]. Taken together, our data suggest that curcumin produces an anti-allodynic effect by activation of NO-cGMP ATP-sensitive $\mathrm{K}^{+}$channels pathways.

\section{Conclusion}

Oral and spinal administration of curcumin reduced tactile allodynia in neuropathic rats. The anti-allodynic effect induced by curcumin was prevented by L-NAME, ODQ, and glibenclamide. These findings suggest that curcumin extenuates the allodynia through the involvement of NO-cGMP-ATP-sensitive $\mathrm{K}^{+}$channel pathways, suggesting that curcumin could be useful for the treatment of neuropathic pain.

\footnotetext{
Abbreviations

\%MPE: Percentage of maximum possible effect; 5- $\mathrm{HT}_{1 \mathrm{~A}}$ : Serotonin 1A receptor; ATP: Adenosine triphosphate; AUC: Area under curve; CFA: Complete freund's adjuvant; cGMP: Cyclic guanosine monophosphate; $\mathrm{CO}_{2}$ : Carbon dioxide; CX3CR1: CX3C chemokine receptor 1; DMSO: Dimethyl sulfoxide; DRG: Dorsal root ganglion; ERK: Extracellular-signal-regulated kinase; F: F-test; HIV: Human immunodeficiency virus; i.t.: intrathecal
}

administration; iNOS: inducible nitric oxide synthase; JNK: c-Jun N-terminal kinase; K+: Potassium; Kg: Kilogram; L5-L6: Lumbar 5 - Lumbar 6; L-NAME: Nnitro-L-arginine methyl ester; LPO: Lipid peroxidation;

LPS: Lipopolysaccharides; ml: milliliter; mRNA: messenger Ribonucleic acid; $\mathrm{NaOH}$ : Sodium hydroxide; NF-k $\beta$ : Nuclear factor kappa-light-chain-enhancer of activated B cells; NO: Nitric oxide; o.p.: oral administration; ODQ: 1H-[1, 2, 4] oxadiazolo [4,3-a]quinoxaline-1-one; p: p-value; S.M.E.: Standard error of the mean; SNL: Spinal Nerve Ligation; $\mu$ microliter; ${ }^{\circ} \mathrm{C}$ : Degree centigrade

\section{Acknowledgments}

No applicable.

\section{Authors'contributions}

TPQ and GSM conducted the experiments. AC analyzed statistical data and wrote the first draft. JPR and GCB conceived the idea, analyzed data and wrote the first draft. GCB wrote the final draft, supervised the experiments, analyzed data, was responsible for funds collections. All authors have read and approved the final manuscripts.

\section{Funding}

The authors are grateful to the financial support from UAM-X (34604032) and from Conacyt (257597). Tracy Pastrana-Quintos was a Conacyt fellow and Arrigo Coen was a DGAPA postdoctoral fellow.

Availability of data and materials

The datasets analyzed during the current study are available from the corresponding author on reasonable request.

\section{Ethics approval and consent to participate}

The protocol No. 148 was previously approved by the Institutional Animal Care Committee at UAM-Xochimilco and in accordance with the Guidelines for Animal Experimentation of the International Association for the Study of Pain (IASP). All animal procedures were carried out in accordance with the Mexican Council for Care and Use of Laboratory Animals and the Norma Oficial Mexicana NOM-062-ZOO-1999. Additionally, every effort was made to minimize pain and suffering, and the number of rats used for the experiment was the minimum number required to obtain significant statistical power. At the end of the experiments, rats were euthanized in a $\mathrm{CO}_{2}$ chamber.

\section{Consent for publication}

Not applicable.

\section{Competing interests}

The authors declare that they have no competing interests.

\section{Author details}

${ }^{1}$ Departamento de Sistemas Biológicos, División de Ciencias Biológicas y de la Salud, Universidad Autónoma Metropolitana-Xochimilco, Calzada del Hueso 1100, Colonia Villa Quietud, 04960 Mexico, D.F., Mexico.

${ }^{2}$ Departamento de Matemáticas, Facultad de Ciencias, Universidad Nacional Autónoma de México, CDMX, Apartado Postal 20-726, 01000 México, Mexico.

Received: 18 October 2019 Accepted: 26 February 2020

Published online: 14 March 2020

\section{References}

1. Finnerup NB, Haroutounian S, Kamerman P, Baron R, Bennett DLH, Bouhassira D, et al. Neuropathic pain: an updated grading system for research and clinical practice. Pain. 2016;157:1599-606.

2. Cavalli E, Mammana S, Nicoletti F, Bramanti P, Mazzon E. The neuropathic pain: an overview of the current treatment and future therapeutic approaches. Int J Immunopathol Pharmacol. 2019;33:1-10.

3. Scholz J, Finnerup NB, Attal N, Aziz Q, Baron R, Bennett MI, et al. The IASP classification of chronic pain for ICD-11: chronic neuropathic pain. Pain. 2019;160:53-9.

4. Chen JJ, Dai L, Zhao LX, Zhu X, Cao S, Gao YJ. Intrathecal curcumin attenuates pain hypersensitivity and decreases spinal neuroinflammation in rat model of monoarthritis. Sci Rep. 2015;5:1-12.

5. Zandi K, Ramedani E, Khosro M, Tajbakhsh S, Dailami I, Rastian Z, et al. Natural product communications evaluation of antiviral activities of Curcumin derivatives. Nat Prod Commun. 2010;5:8-11. 
6. Llano S, Gómez S, Londoño J, Restrepo A. Antioxidant activity of curcuminoids. Phys Chem Chem Phys. 2019;21:3752-60.

7. Pluta R, Ułamek-Kozioł M, Czuczwar SJ. Neuroprotective and neurological/ cognitive enhancement effects of curcumin after brain ischemia injury with alzheimer's disease phenotype. Int J Mol Sci. 2018;19(12):1-16.

8. Ceremuga TE, Helmrick K, Kufahl Z, Kelley J, Keller B, Philippe F, et al. Investigation of the anxiolytic and antidepressant effects of curcumin, a compound from turmeric (curcuma longa), in the adult male Spraguedawley rat. Holist Nurs Pract. 2017;31:193-203.

9. Zhang Z, Leong DJ, Xu L, He Z, Wang A, Navati M, et al. Curcumin slows osteoarthritis progression and relieves osteoarthritis-associated pain symptoms in a post-traumatic osteoarthritis mouse model. Arthritis Res Ther. 2016;18:1-12.

10. Zhang $Y$, Zeng $Y$. Curcumin reduces inflammation in knee osteoarthritis rats through blocking TLR4 /MyD88/NF-kB signal pathway. Drug Dev Res. 2019; 80:353-9.

11. Tajik H, Tamaddonfard E, Hamzeh-Gooshchi N. The effect of curcumin (active substance of turmeric) on the acetic acid-induced visceral nociception in rats. Pakistan J Bioloical Sci. 2008;11:312-4.

12. Gaffey A, Campbell J, Porritt $K$, Slater $H$. The effects of curcumin on musculoskeletal pain: a systematic review protocol. JBI Database Syst Rev Implement Rep. 2015;13:59-73.

13. Cheppudira B, Fowler M, McGhee L, Greer A, Mares A, Petz L, et al. Curcumin: a novel therapeutic for burn pain and wound healing. Expert Opin Investig Drugs. 2013;22:1295-303.

14. Di YX, Hong C, Jun L, Renshan G, Qinquan L. Curcumin attenuates mechanical and thermal Hyperalgesia in chronic constrictive injury model of neuropathic pain. Pain Ther. 2014;3:59-69.

15. Jeon Y, Kim CE, Jung D, Kwak K, Park S, Lim D, et al. Curcumin could prevent the development of chronic neuropathic pain in rats with peripheral nerve injury. Curr Ther Res - Clin Exp. 2013;74:1-4.

16. Cao H, Ge R, Li J, Li J, Meng B, Zheng J. Effects of curcumin on pain threshold and on the expression of nuclear factor $\mathrm{KB}$ and $\mathrm{CX} 3 \mathrm{C}$ receptor 1 after sciatic nerve chronic constrictive injury in rats. Chin J Integr Med. 2014; 20:850-6.

17. Zhao X, Xu Y, Zhao Q, Chen CR, Liu AM, Huang ZL. Curcumin exerts antinociceptive effects in a mouse model of neuropathic pain: descending monoamine system and opioid receptors are differentially involved. Neuropharmacology. 2012;62:843-54.

18. Babu A, Prasanth KG, Balaji B. Effect of curcumin in mice model of vincristine-induced neuropathy. Pharm Biol. 2015;53:838-48.

19. Cury Y, Picolo G, Gutierrez VP, Ferreira SH. Pain and analgesia: the dual effect of nitric oxide in the nociceptive system. Nitric Oxide. 2011;25:243-54.

20. Bermúdez-Ocaña DY, Ambriz-Tututi M, Pérez-Severiano F, Granados-Soto V Pharmacological evidence for the participation of NO-cyclic GMP-PKG-K+ channel pathway in the antiallodynic action of resveratrol. Pharmacol Biochem Behav. 2006;84:535-42.

21. de los Monteros-Zuñiga AE, Izquierdo T, Quiñonez-Bastidas GN, RochaGonzález HI, Godínez-Chaparro B. Anti-allodynic effect of mangiferin in neuropathic rats: Involvement of nitric oxide-cyclic GMP-ATP sensitive K+ channels pathway and serotoninergic system. Pharmacol Biochem Behav. 2016;150-151:190-7.

22. Izquierdo T, Espinosa De Los Monteros-Zuñiga A, Cervantes-Durán C, Lozada MC, Godínez-Chaparro B. Mechanisms underlying the antinociceptive effect of mangiferin in the formalin test. Eur J Pharmacol. 2013;718:393-400

23. Mata-Bermudez A, Izquierdo T, de los Monteros-Zuñiga E, Coen A, GodínezChaparro B. Antiallodynic effect induced by [6]-gingerol in neuropathic rats is mediated by activation of the serotoninergic system and the nitric oxidecyclic guanosine monophosphate-adenosine triphosphate-sensitive K+ channel pathway. Phyther Res. 2018;32:2520-30

24. Zulazmi NA, Gopalsamy B, Min JCS, Farouk AAO, Sulaiman MR, Bharatham $\mathrm{BH}$, et al. Zerumbone alleviates neuropathic pain through the involvement of L-arginine-nitric oxide-cGMP-K+ ATP Channel pathways in chronic constriction injury in mice model. Molecules. 2017;22:1-16.

25. De Carvalho VC, Rodrigues VG, Ferreira RCM, Duarte LP, Klein A, Duarte ID, et al. Tingenone, a pentacyclic triterpene, induces peripheral antinociception due to NO/cGMP and ATP-sensitive $\mathrm{K}^{+}$channels pathway activation in mice. Eur J Pharmacol. 2015;755:1-5.

26. Quinõnez-Bastidas GN, Pineda-Farias JB, Flores-Murrieta FJ, RodriquezSilverio J, Reyes-Garcia JG, Godínez-Chaparro B, et al. Antinociceptive effect of (-)-epicatechin in inflammatory and neuropathic pain in rats. Behav Pharmacol. 2018:29:270-9.

27. De Paz-Campos MA, Chávez-Piña AE, Ortiz Ml, Castañeda-Hernández G. Evidence for the participation of ATP-sensitive potassium channels in the antinociceptive effect of curcumin. Korean J Pain. 2012;25:221-7.

28. Caram-Salas NL, Reyes-García G, Bartoszyk GD, Araiza-Saldaña Cl, AmbrizTututi M, Rocha-González HI, et al. Subcutaneous, intrathecal and periaqueductal grey administration of asimadoline and ICl-204448 reduces tactile allodynia in the rat. Eur J Pharmacol. 2007;573:75-83.

29. Kroin JS. Kroin 2003 no sex diffrents in postoperative model-2. 2003;50(9): 904-8.

30. Zimmermann M. Ethical guidelines for investigations of experimental pain in conscious animals. Pain. 1983;16:109-10.

31. Ho Kim S, Mo CJ. An experimental model for peripheral neuropathy produced by segmental spinal nerve ligation in the rat. Pain. 1992;50:35563.

32. Chaplan SR, Bach FW, Pogrel JW, Chung JM, Yaksh TL. Quantitative assessment of tactile allodynia in the rat paw. J Neuroci Methods. 1994; 53(1):55-63.

33. Dixon WJ. Efficient analysis of experimental observation. Annu Rev Pharmacol Toxicol. 1980;20:441-62.

34. Mestre C, Pélissier T, Fialip J, Wilcox G, Eschalier A. A method to perform direct transcutaneous intrathecal injection in rats. J Pharmacol Toxicol Methods. 1994;32:197-200.

35. Wallin J, Cui JG, Yakhnitsa V, Schechtmann G, Meyerson BA, Linderoth B. Gabapentin and pregabalin suppress tactile allodynia and potentiate spinal cord stimulation in a model of neuropathy. Eur J Pain. 2002;6:261-72.

36. Mixcoatl-Zecuatl T, Medina-Santillán R, Reyes-García G, Vidal-Cantú GC, Granados-Soto V. Effect of K+ channel modulators on the antiallodynic effect of gabapentin. Eur J Pharmacol. 2004;484:201-8.

37. Mixcoatl-Zecuatl T, Flores-Murrieta FJ, Granados-Soto V. The nitric oxidecyclic GMP-protein kinase G-K + channel pathway participates in the antiallodynic effect of spinal gabapentin. Eur J Pharmacol. 2006;531:87-95.

38. Zhao X, Wang C, Zhang JF, Liu L, Liu AM, Ma Q, et al. Chronic curcumin treatment normalizes depression-like behaviors in mice with mononeuropathy: involvement of supraspinal serotonergic system and GABA $A_{A}$ receptor. Psychopharmacology. 2014;231:2171-87.

39. Ocaña M, Cendán CM, Cobos EJ, Entrena JM, Baeyens JM. Potassium channels and pain: present realities and future opportunities. Eur J Pharmacol. 2004;500:203-19.

40. Yamazumi I, Okuda T, Koga Y. Involvement of potassium channels in spinal antinociceptions induced by fentayl, clonidine and bethanechol in rats. Jpn J Pharmacol. 2001;87:268-76.

41. Pan MH, Lin-Shiau SY, Lin JK. Comparative studies on the suppression of nitric oxide synthase by curcumin and its hydrogenated metabolites through down-regulation of $\mathrm{k} B$ kinase and $\mathrm{NFKB}$ activation in macrophages. Biochem Pharmacol. 2000;60:1665-76.

42. Jung KK, Lee HS, Cho JY, Shin WC, Rhee MH, Kim TG, et al. Inhibitory effect of curcumin on nitric oxide production from lipopolysaccharide-activated primary microglia. Life Sci. 2006;79:2022-31.

43. Hao JX, Xu XJ. Treatment of a chronic allodynia-like response in spinally injured rats: effects of systemically administered nitric oxide synthase inhibitors. Pain. 1996:66:313-9.

\section{Publisher's Note}

Springer Nature remains neutral with regard to jurisdictional claims in published maps and institutional affiliations.

\section{Ready to submit your research? Choose BMC and benefit from}

- fast, convenient online submission

- thorough peer review by experienced researchers in your field

- rapid publication on acceptance

- support for research data, including large and complex data types

- gold Open Access which fosters wider collaboration and increased citations

- maximum visibility for your research: over $100 \mathrm{M}$ website views per year

At $\mathrm{BMC}$, research is always in progress.

Learn more biomedcentral.com/submission 